\title{
MANAGEMENT OF ENDOCRINE DISEASE Differential diagnosis, investigation and therapy of bilateral adrenal incidentalomas
}

\author{
Isabelle Bourdeau, Nada El Ghorayeb, Nadia Gagnon and André Lacroix \\ Division of Endocrinology, Department of Medicine, Centre de recherche du Centre hospitalier de I'Université de \\ Montréal (CRCHUM), Université de Montréal, Montréal, Canada
}

Correspondence

should be addressed

to I Bourdeau

Email

isabelle.bourdeau@

umontreal.ca

\begin{abstract}
The investigation and management of unilateral adrenal incidentalomas have been extensively considered in the last decades. While bilateral adrenal incidentalomas represent about $15 \%$ of adrenal incidentalomas (Als), they have been less frequently discussed. The differential diagnosis of bilateral incidentalomas includes metastasis, primary bilateral macronodular adrenal hyperplasia and bilateral cortical adenomas. Less frequent etiologies are bilateral pheochromocytomas, congenital adrenal hyperplasia (CAH), Cushing's disease or ectopic ACTH secretion with secondary bilateral adrenal hyperplasia, primary malignancies, myelolipomas, infections or hemorrhage. The investigation of bilateral incidentalomas includes the same hormonal evaluation to exclude excess hormone secretion as recommended in unilateral Al, but diagnosis of $\mathrm{CAH}$ and adrenal insufficiency should also be excluded. This review is focused on the differential diagnosis, investigation and treatment of bilateral Als.
\end{abstract}

\section{Introduction}

Adrenal incidentaloma (AI) is a mass larger than $1 \mathrm{~cm}$ in diameter discovered incidentally on imaging not performed for suspected adrenal disease (1). Adrenal lesions detected on screening imaging for patients with cancer or hereditary syndromes are outside of this definition. Advances in imaging techniques raised the prevalence of AI to $4.4 \%$ in radiological series compared to autopsy data $(1-8.7 \%)(1,2,3,4,5)$. The prevalence is higher in patients with obesity, diabetes or hypertension (6) and is increasing with age reaching $7-10 \%$ in individuals older than 70 years old $(7,8,9)$. Although the majority of AIs are unilateral tumors bilateral AIs are found in up to $15 \%$ of cases $(10,11)$. Thus, the prevalence of bilateral AI can be estimated to be $0.3-0.6 \%$ in the general population.

\section{Invited Author's profile}

Isabelle Bourdeau is Professor of Medicine in the Division of Endocrinology at Centre hospitalier de l'Université de Montréal (CHUM) and researcher at CHUM research center since 2004. In 2005, she established a new clinic focusing on genetics of adrenal tumors at CHUM. She is the National Delegate/PI for Canada of the American-Australian-Asian Adrenal Alliance (A5). As a clinicianscientist she performs translational research in adrenal diseases. Her research interests include genetics of adrenal tumors and the role of Wnt/beta-catenin signaling in adrenocortical tumor

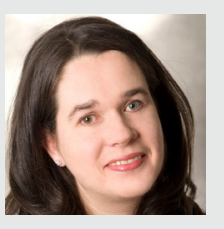
development.

(C) 2018 European Society of Endocrinology Printed in Great Britain
Published by Bioscientifica Ltd. 
Approach to unilateral AI has been discussed extensively in the past two decades $(1,9,12,13,14)$, but no attention was devoted to bilateral AI. We will review here the etiologies, the investigation and management of bilateral AI focusing on adult population.

\section{Etiologies}

The causes of unilateral or bilateral AI vary depending whether recruitment was from endocrinology clinics or from surgical series where adrenal cancers and secreting tumors are overrepresented leading to overestimation of the real prevalence of malignancy. A recent study confirmed the conclusions of a meta-analysis demonstrating that malignancy rate is low being $0.6-1.4 \%$ for adrenocortical carcinomas and $0.2-2.2 \%$ for metastasis in true AI being referred to endocrinology; benign non-secreting tumors represent more than $80-85 \%$ of $\mathrm{AI}(11,15)$. We will describe below various etiologies of bilateral AIs that are summarized in Table 1.

The distribution of etiologies of bilateral AI differs from that of unilateral AI; two studies including 887 and 202 patients found that the most common causes of bilateral AI were metastasis, primary bilateral macronodular

Table 1 Differential diagnosis of most common causes of bilateral adrenal incidentalomas.

\begin{tabular}{l}
\hline Extra adrenal lesions \\
Kidney, pancreas and spleen lesions \\
Technical artifacts \\
Adrenal lesions \\
Tumoral \\
Adrenal tumors and hyperplasias \\
Bilateral macronodular adrenal hyperplasia \\
Adenomas \\
Pheochromocytoma \\
Adrenocortical carcinoma \\
Congenital adrenal hyperplasia \\
Glucocorticoid resistance syndrome \\
ACTH-dependent hyperplasia \\
Cushing's disease \\
Ectopic ACTH Cushing's syndrome \\
Non-adrenal tumors \\
Metastases \\
Lymphoma \\
Myelolipomas \\
Infections \\
Tuberculosis \\
Histoplasmosis \\
Blastomycosis \\
Infiltrative \\
Amyloidosis \\
Adrenal hemorrhage
\end{tabular}

adrenal hyperplasia (BMAH) (Fig. 1A) and bilateral cortical adenomas $(16,17)$. Other causes of bilateral AI include bilateral pheochromocytomas (Fig. 2), congenital adrenal hyperplasia $(\mathrm{CAH})$, Cushing's disease or ectopic ACTH secretion with secondary bilateral adrenal hyperplasia $(17,18,19,20)$ (Table 1).

\section{Adrenal metastasis or malignancies}

In a study involving 208 patients with AI including 172 unilateral AI and 36 bilateral AI, 19 (9\%) patients had metastatic adrenal lesions and among them ten had bilateral adrenal lesions (21). The primary cancers leading to adrenal metastases in this study included kidney, bronchogenic carcinoma, colon, stomach and breast cancers (21). Bilateral adrenal metastases were also described in melanoma, thyroid cancer, sarcomatoid hepatocellular carcinoma and bladder cancer.

For patients with adrenal lesions with malignancy or who are at high risk for malignancy, adrenal biopsy may be indicated for staging work-up. Moreover, although recurrences most frequently occur locoregionally, in few patients, they may present with only distant unilateral or very rarely bilateral adrenal metastases that may be synchronous or metachronous. The overall sensitivity of adrenal biopsy for malignancy is of $87 \%$ with a specificity of $100 \%$ (14). Bilateral metastasis may lead to adrenal insufficiency due to neoplastic infiltration of the adrenal glands as described in patients with small-cell lung cancer (22).

Very rare case reports of bilateral adrenal gland metastasis were reported in patients with renal cell
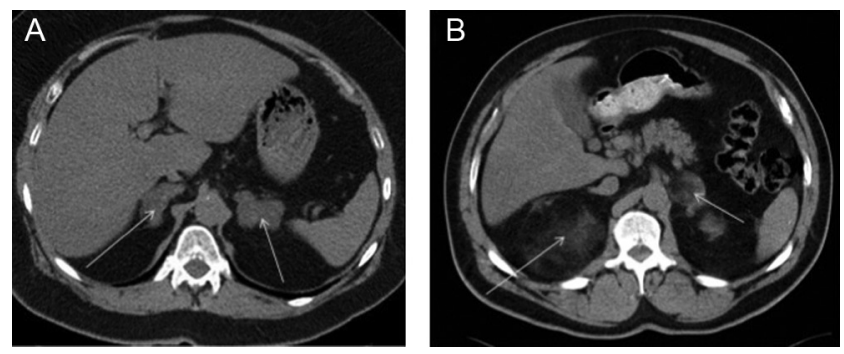

\section{Figure 1}

CT scan imaging of bilateral adrenal lesions. (A) Classical findings of bilateral macronodular adrenal hyperplasia. (B) Bilateral adrenal myelolipomas (right: $10.7 \times 9.5 \mathrm{~cm}$ and left: $3.9 \times 4.3 \mathrm{~cm}$ ) showing classical features of myelolipomas with well-defined fat attenuating in the lesions. The arrows are pointing to the adrenal glands. 


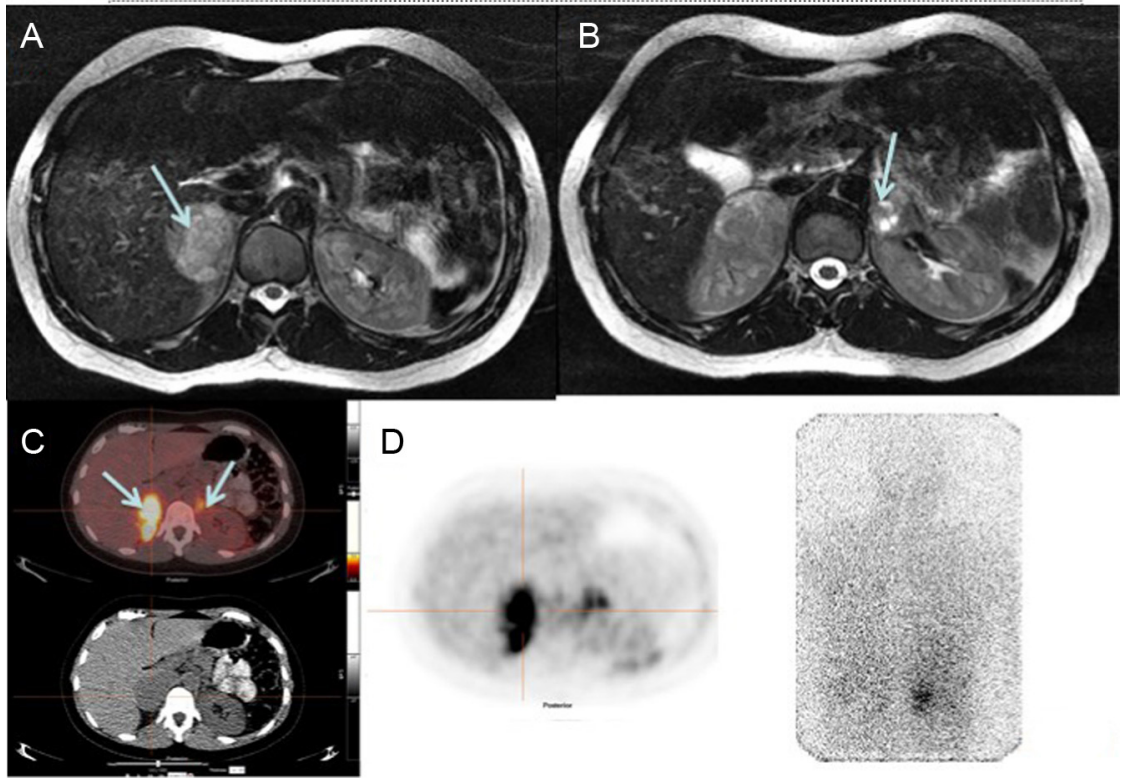

\section{Figure 2}

Bilateral pheochromocytomas in a 28-year-old woman. (A) MRI showing a $4.7 \times 4.4 \mathrm{~cm}$ right adrenal mass and a $2.9 \times 2.9$ left adrenal mass (B). The masses are hypointense on T1-weighted image, and in both lesions, there are areas of hyperintensity on T2-weighted images. (C) Both adrenal lesions showed uptake at FDG-PET with a SUVmax of 5.4 on the right side and 4.6 on the left side. (D) MIBG was positive only on the right adrenal gland. Diagnosis of bilateral pheochromocytomas was confirmed at pathology after bilateral adrenalectomies.

carcinoma. Surgical resection of metastases is the only therapeutic option for these patients. Both bilateral adrenalectomies and total adrenalectomy on one side and partial adrenalectomy on the contralateral side to preserve adrenal hormonal function were reported $(23,24)$.

Other less frequent neoplastic causes of bilateral AI include the rare bilateral adrenocortical carcinomas and lymphoma. A recent French cohort of 28 patients with adrenal lymphoma reported a prevalence of bilateral adrenal lymphoma of $71 \%$ (25). The initial symptoms were a worsening general state, weight loss and abdominal pain associated with classical biological features of lymphoma such as increased LDH, ß2microglobulin, CRP or ferritin levels. Importantly, adrenal insufficiency was found in 8 of 11 patients (73\%) with bilateral lymphoma (25). Patients with adrenal lymphoma do not undergo adrenalectomy as they are treated with systemic chemotherapy.

\section{Bilateral macronodular adrenal hyperplasia}

Bilateral adrenal hyperplasia can either present as macronodular (nodules $>1 \mathrm{~cm}$ ) or micronodular (nodules $<1 \mathrm{~cm})$. The micronodular form includes primary pigmented nodular adrenal disease (PPNAD) that is most often not associated with dominant adrenal nodules except for rare cases (26). For this reason, PPNAD does not usually present as AI, and it will not be further discussed in this review. Similarly, we will not discuss extensively primary aldosteronism, which is secondary to bilateral adrenal hyperplasia in approximately $60 \%$ of cases as they may have normal-appearing adrenal glands on CT and are rarely investigated in the course of evaluation of AIs (27).

$\mathrm{BMAH}$ is suspected when there is bilateral AI with incomplete suppression to $1 \mathrm{mg}$ dexamethasone overnight test. Cortisol secretion is in part regulated by the expression of multiple aberrant $G$ protein-coupled receptors (GPCRs) in zona fasciculata cells including those for vasopressin, serotonin, luteinizing hormone/human chorionic gonadotropin, $\beta$-adrenergic agonists, GIP, glucagon and angiotensin II (28). These GPCRs led to the activation of cyclic AMP/protein kinase A (PKA) signaling pathway in a similar fashion to the pathway activated by ACTH receptor consequently leading to the transcription of steroidogenic factors. GPCRs were identified in $80 \%$ of patients with overt or mild hypercortisolism (28). Several simultaneous aberrant receptor responses were demonstrated in half of the patients with BMAH: vasopressin and serotonin being the stimuli leading to the highest number of aberrant responses in vivo $(29,30$, $31,32,33)$. The presence of aberrant responses was less frequent in patients with unilateral adenomas and overt hypercortisolism (29) probably due to the high frequency of mutations in the catalytic subunit of PKA (PRKACA) in those patients (34). The concept of ACTH-independent cortisol secretion was challenged after the demonstration of paracrine and autocrine production of ACTH in tissues of BMAH regulating cortisol production $(35,36)$.

On unenhanced CT, both adrenal glands are enlarged usually with multiple nodules (Figs 1A and 3), but diffuse adrenal enlargement without nodules is also seen. Attenuation higher than $10 \mathrm{HU}$ was also described (37). 

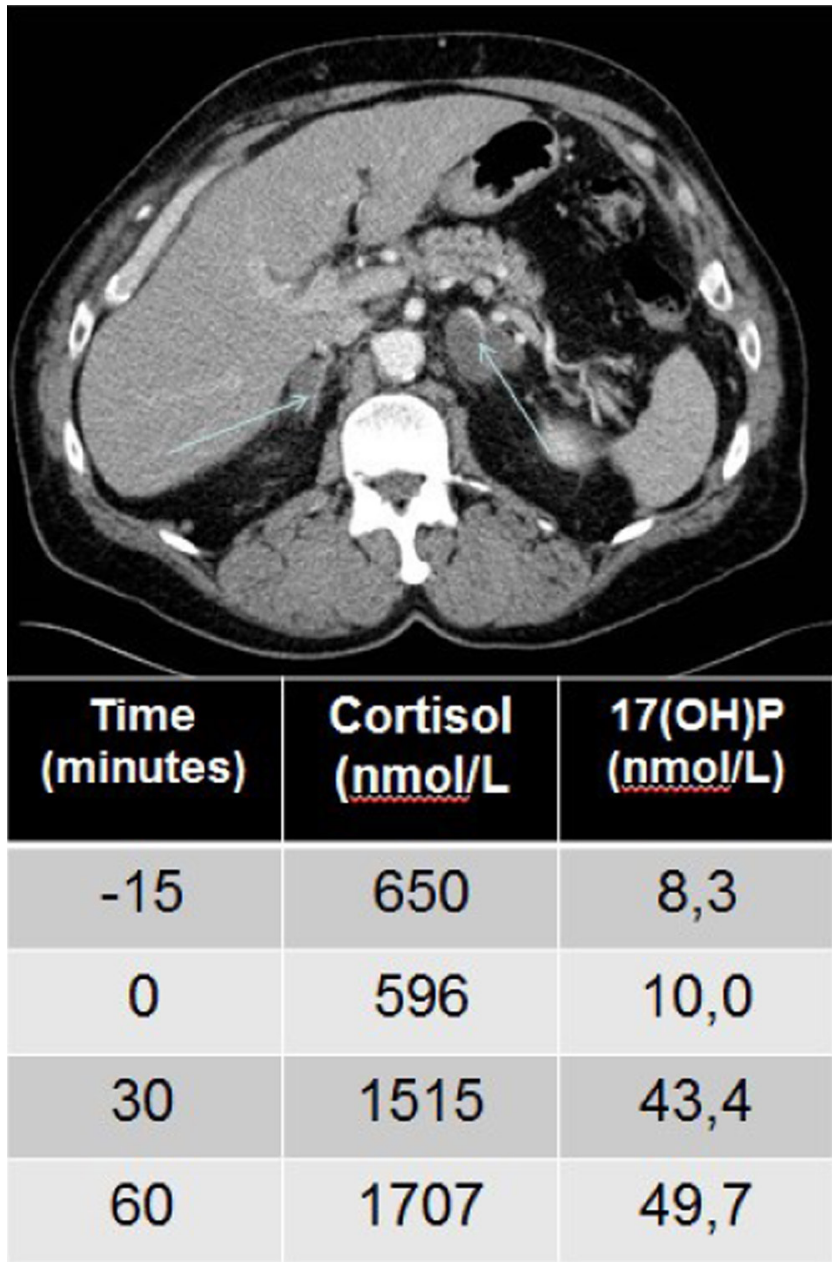

Figure 3

Adrenal CT scan of a 69-year-old man who presented with bilateral incidentalomas. The left adrenal gland has two nodular lesions of $3 \times 2 \mathrm{~cm}$ and $1.6 \times 1.3 \mathrm{~cm}(11 \mathrm{HU})$, whereas the right adrenal gland has a nodule of $1.8 \times 0.8 \mathrm{~cm}$. All nodules were stable in size from 2006 to 2017 . The hormonal investigation was normal. Including the $1 \mathrm{mg}$ dexamethasone suppression test. The $250 \mu \mathrm{g}$ cosyntropin test showed overproduction of serum cortisol and 17-hydroxyprogesterone supporting the diagnosis of bilateral macronodular adrenal hyperplasia.

In contrast-enhanced imaging, nodules can have marked enhancement, and there might be enhancement of the periphery of the glands. An asymmetric appearance is possible and may be confused with a unilateral disease. On MR, relative to the liver, glands are usually hypointense on T1-weighted images and hyperintense on T2-weighted images (38).

In limited studies using 2-(fluorine 18) fluoro-2dexoxy-D glucose positron emission tomography/CT
(PET/CT) imaging, uptake in the macronodular adrenal glands of BMAH was higher than the liver, with maximum standardized uptake value (SUV max) $>3.1$ (3.3-8.9), thus reaching level usually seen in malignant tumors $(37,39)$ although BMAH is well recognized as a benign disease. These findings need to be confirmed in larger series.

\section{Pheochromocytomas}

Bilateral adrenal pheochromocytomas are more likely associated to a hereditary cause compared to unilateral pheochromocytomas (40). Bilateral adrenal pheochromocytomas may be found in association with multiple endocrine neoplasia type $2 \mathrm{~A}$ and type $2 \mathrm{~B}$, von Hippel-Lindau syndrome and have been reported in patients with neurofibromatosis type 1 as well (41). More recently, germline mutations of the tumor suppressor susceptibility gene, MAX (MYC-associated factor X), were identified in a large cohort of pheochromocytomas and paragangliomas with a prevalence of $1.12 \%$ (42). Among the 19 patients harboring a pathogenic germline MAX mutations, 11 had developed bilateral pheochromocytomas (42). Thus, caregivers should look for underlying genetic syndromes and offering a genetic counseling to patients with bilateral pheochromocytomas knowing that the probability to identify a germline genetic cause is higher than that in unilateral pheochromocytoma. Pheochromocytomas are hypervascular, then they have intense enhancement during the arterial phase of CT scan. Similarly, in MRI, they show hyperenhancement following injection of gadolinium and classically they are hyperintense on T2-weighted images (43).

\section{Congenital adrenal hyperplasia}

In patients with $\mathrm{CAH}$, chronic elevation of ACTH leads to adrenal tumors in $82 \%$ of cases. The occurrence of 21-hydroxylase-gene mutation (CYP21) in patients with unilateral AI and bilateral AI was found at similar frequency with a prevalence of $16.1 \%$ and $21.1 \%$ respectively (44). A meta-analyses of 36 publications on $\mathrm{CAH}$ and adrenal tumors suggested that bilateral AI may predict $\mathrm{CAH}$; one-third of biochemically confirmed $\mathrm{CAH}$ had bilateral $\mathrm{AI}$ and this frequency was increased to $50 \%$ in the subgroup of patients with genetically confirmed $\mathrm{CAH}$, which is much higher than the expected prevalence of $15 \%$ of bilateral AI (45). Nodular adrenal hyperplasia 
occurs in ACTH-dependent Cushing's syndrome particularly in older patients and those with a longer standing disease (46).

\section{Other causes of bilateral Al}

Among the less frequent causes of bilateral adrenal lesions are adrenal myelolipoma (Fig. 1B), benign tumors composed of mature adipose cells and hematopoietic tissue. They may be diagnosed incidentally, due to mass effect symptoms or rarely hormonal-secreting symptoms if there is a compound associated hormone-secreting tumor in the same adrenal. Myelolipomas show specific characteristics at noncontrast CT with hypoattenuation of 130-23 HU containing macroscopic fat (47). At MRI, macroscopic fat appears hyperintense on T1-weighted images, whereas the marrow elements are $\mathrm{T} 1$ hypointense but of variable intensity on T2 signal (43). Less than 40 cases of bilateral adrenal myelolipomas have been reported so far (48). Surgical removal should be reserved for secreting myelolipomas and or those larger lesions $(>6-7 \mathrm{~cm})$ that may cause pain or be prone to rupture of hemorrhage $(48,49)$.

Non-tumoral causes of bilateral adrenal enlargement include infections such as tuberculosis, histoplasmosis and blastomycosis. The adrenal glands are among the most common sites involved in disseminated histoplasma infections in immunocompetent individuals and bilateral adrenal enlargement has been reported (50). Longterm infection may lead to adrenal glands destruction and adrenal insufficiency. Infiltrative diseases such as amyloidosis are part of the differential diagnosis of bilateral adrenal lesions that may be found incidentally.

Adrenal hemorrhage may be found bilaterally and may result in acute primary adrenal insufficiency (51). Predisposing factors include trauma, anticoagulation therapy, antiphospholipid syndrome, sepsis such as meningococcemia (Waterhouse-Friderichsen syndrome) and stress as surgery $(51,52)$. Adrenal hemorrhage is recognized in noncontrast CT showing hyperdense adrenal enlargement. Follow-up in these cases is essential to eliminate underlying adrenal tumoral lesions.

\section{Hormonal work-up for bilateral Als}

The initial work-up for bilateral AI is similar to unilateral $\mathrm{AI}$ and is based on two main clinical questions; 1 ) do these lesions secrete excess hormones? 2) Are they malignant masses? The assessment should include a detailed questionnaire and physical examination of the patients to assess the signs of adrenal hormones oversecretion. The investigation should be able to identify even mild adrenal hormone excess $(1,10,12,14,53)$. In contrast to unilateral AI, adrenal insufficiency and CAHs should be excluded specifically for patients with bilateral AI. Cortisol excess should be excluded in all patients with a $1 \mathrm{mg}$ dexamethasone suppression test (1 mg DST). DST requires taking $1 \mathrm{mg}$ oral dexamethasone at $23 \mathrm{~h}$ or $24 \mathrm{~h}$ then measuring cortisol level the next morning at $8 \mathrm{~h}-9 \mathrm{~h}$; normal levels should be $<50 \mathrm{nmol} / \mathrm{L}$. Evaluation of catecholamines excess is performed either by a 24-h urinary collection of metanephrines and fractionated catecholamines or by measuring free plasma levels of free metanephrines and normetanephrines after 30 minutes of rest in supine posture (54). When arterial hypertension or hypokalemia are present, plasma aldosterone and renin after 15 minutes of sitting position should be performed to detect primary aldosteronism. Additional specific samplings should be done according to clinical suspicion including estrogens in the presence of gynecomastia and DHEAS, total testosterone, SHBG in the presence of hirsutism/virilization or suspicion of adrenocortical carcinoma.

Two additional investigations should be performed specifically in bilateral AI. First, adrenal insufficiency should be ruled out because destruction of more than $90 \%$ of the cortex of both glands may lead to adrenal insufficiency. Second, late-onset forms of CAH (specially 21-hydroxylase deficiency) may be diagnosed late in adulthood. For this fasting blood samples for cortisol, 17-hydroxyprogesterone and ACTH are obtained early morning and depending on the results may be followed by stimulation with $250 \mu \mathrm{g}$ of ACTH 1-24 where levels of cortisol and 17-hydroxyprogesterone are measured at 30 and $60 \mathrm{~min}$ later. Adrenal insufficiency is present when cortisol increase is incomplete $(<430-550 \mathrm{nmol} / \mathrm{L}$ depending the method of measurement) and basal ACTH levels are high. Samples of plasma aldosterone and renin in sitting position are then indicated to evaluate the requirement for mineralocorticoids replacement. Increased levels of basal and post $250 \mu \mathrm{g}$ ACTH stimulation test of 17-hydroxyprogesterone (17-hydroxyprogesterone $>43 \mathrm{nmol} / \mathrm{L})$ (55) could reveal a partial congenital deficiency in 21-hydroxylase. However, screening for CAH with 17-hydroxyprogesterone may lack specificity and CYP21A2 mutation analyses will be the most reliable test for $\mathrm{CAH}$ diagnosis confirmation. A mild enzymatic deficiency with modest rise in 17-hydroxyprogesterone 
is also frequently found in adenomas and BMAH (31). In these cases, we should expect that ACTH levels could discriminate between CAH (increased ACTH), whereas ACTH levels are within or below the normal limit values usually in BMAH. In patients with BMAH, following a $250 \mu \mathrm{g}$ cosyntropin test, an overproduction of plasma cortisol and 17-hydroxyprogesterone levels reflect the mass of hyperplastic adrenal glands with relative deficiency of 21 hydoxylase expression (31) (Fig. 3). It should be kept in mind that the nature of the bilateral adrenal lesions may be different in the two sides with a secreting adrenal lesion on one side and a non-secreting on the other side (Fig. 4).

\section{Modest secretion of cortisol is more frequent in bilateral Als than in unilateral Als}

A cortisol-secreting adenoma with overt Cushing symptoms rarely presents as an AI (0.8\%) (11) while adenomas with modest cortisol secretion (previously termed subclinical Cushing syndrome) are found in up to $25 \%$ of AI $(13,56)$. Modest cortisol secretion that is not high enough to result in classical clinical stigmata

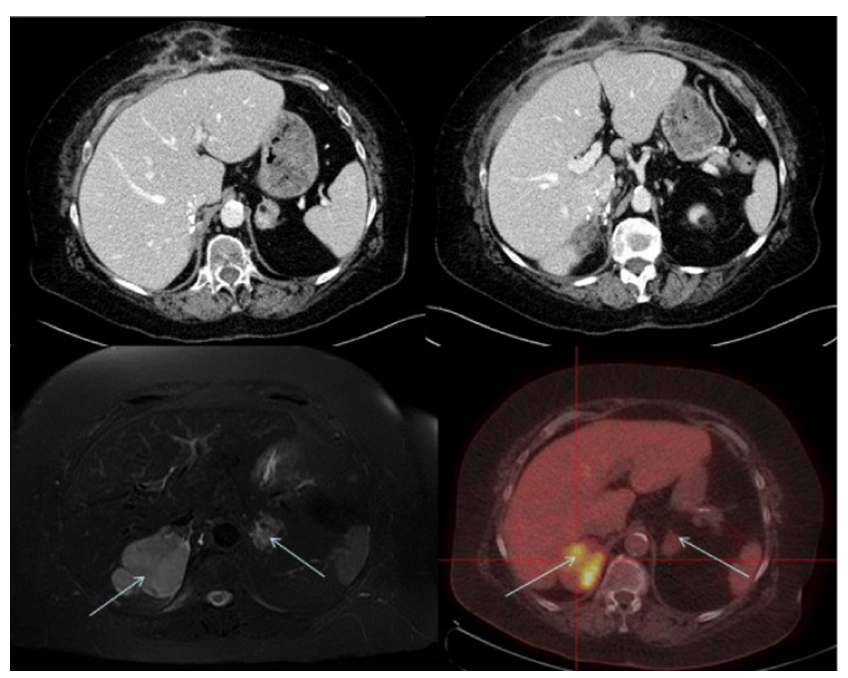

\section{Figure 4}

Bilateral adrenal lesions in a 78-year-old woman with Cushing's syndrome and hyperandrogenism. She was initially referred for bilateral adrenocortical carcinomas. Revised CT scan showed a right $5.9 \times 7.7 \mathrm{~cm}$ lesion suggesting an adrenocortical carcinoma ( $36 \mathrm{HU}$ ) with SUVmax of 9.5 at FDG-PET and a $2.7 \times 2.1 \mathrm{~cm}$ left adrenal mass compatible with an adenoma with low HU and lower SUVmax (SUVmax 3.8). of Cushing syndrome was recently termed (possible) autonomous (for non-ACTH-dependent) cortisolsecretion (14). Its biochemical definition varied among authors and to date, there is still no consensus on its diagnostic criteria $(14,57)$ except for a serum cortisol post dexamethasone between 51 and $140 \mathrm{nmol} / \mathrm{L}$ for possible autonomous cortisol secretion and autonomous cortisol secretion for higher values. Nevertheless, patients secreting mild cortisol excess might carry an increased risk of osteoporotic, metabolic and cardiovascular complications compared to control patients matched for age, gender and BMI $(2,58,59)$. In 2014, Di Damalzi et al. studied a retrospective cohort of patients with AIs and found that survival rates for all-cause mortality were lower in patients with abnormal suppression to $1 \mathrm{mg}$ DST ( $>50 \mathrm{nmol} / \mathrm{L}$ ) compared to patients with non-secreting adrenal masses (60). Factors associated with mortality were age and mean concentration of cortisol post DST (60). Similarly, in 2014, Debono et al. assessed survival in a retrospective cohort of 206 patients with AIs. There was a significant decrease in survival rate (deaths were mainly due to circulatory or respiratory/infectious causes) with increasing post-dexamethasone serum cortisol level (61).

Morelli et al. compared prospectively 175 unilateral AI to 38 bilateral AI; the prevalence of mild cortisol excess, hypertension, diabetes type 2 and dyslipidemia were comparable between the two groups, whereas fractures were more frequent in patients with bilateral AI (62).

In 2011, Vassiliadi et al. reported in a retrospective cohort of adrenal incidentalomas that mild cortisol excess was more frequent in bilateral AI vs unilateral AI with a prevalence of $41.5 \%$ vs $12.2 \%$ (63). An other study in 2011 by Androulakis et al. showed that patients with bilateral AI have more pronounced cortisol and aldosterone secretion and glucose metabolism alterations than patients with unilateral AI (64). These data were confirmed in a prospective study of 224 unilateral AI and 74 bilateral AI, where mild cortisol excess was present in $35.1 \%$ of patients with bilateral AI, but only in $17.9 \%$ of patients with unilateral AI (65). However, hypertension, diabetes type 2 and dyslipidemia were comparable in both groups (65). More recently, in a surgical series including 112 unilateral $\mathrm{AI}$ and 23 bilateral AI, mild cortisol excess was present in $21.7 \%$ bilateral AI vs $6.2 \%$ of unilateral AI (66). Vassiliadi et al. demonstrated an exaggerated response of cortisol and ACTH in patients with bilateral AI during the combined test of DST followed by CRH stimulation compared to unilateral $\mathrm{AI}$ and to a control group suggesting that the regulation of hypothalamicpituitary axis was disturbed in patients with bilateral AI; 
nevertheless, the diagnosis of BMAH was not excluded in this group (67).

\section{BMAH and ARMC5 gene mutations}

Inactivating germline mutations of Armadillo repeat containing 5 (ARMC5) gene were identified in 55\% of the first series of 33 apparently sporadic cases of BMAH with Cushing's syndrome (68). The prevalence of these mutations is closer to $25 \%$ based on larger recent studies $(34,69,70)$. The germline mutation is responsible for the diffuse hyperplasia and additional somatic mutations are necessary for the formation of different macronodules $(68,70)$. The possible association between ARMC5 mutations and the expression of aberrant receptors has been described $(68,70,71,72)$ as well as the association between these mutations and the presence of other tumors such as meningiomas suggesting the possibility of a new multiple neoplasia syndrome (73) Although ARMC5 mutations are the most common genetic alterations described in BMAH, no clear ARMC5 genotype-phenotype correlations were identified (72). Very recently, Emms et al. investigated whether ARMC5 mutations play a role in the development of incidentally discovered bilateral adrenal nodules (74) Among the 39 patients included in their study, only one patient carried a likely pathogenic ARMC5 mutation (74).

Other genetic alterations could be associated with BMAH such as in the menin (MEN1), fumarate hydratase (FH) and adenomatosis polyposis coli (APC) genes $(33,75$, 76, 77).

In all cases, these gene mutations have an autosomal dominant mode of transmission; thus, clinicians should be aware that patients may develop BMAH in the context of hereditary syndromes. Evaluation of BMAH patients should include a detailed family history, and a reference for specialized genetic counseling. Genetic testing should be offered and then be available to first-degree relatives of individuals who carry a germline mutation. Several individuals from BMAH families described previously were affected by various degrees of cortisol excess mainly obesity, hypertension and diabetes and had unsuspected BMAH before systematic clinical and genetic screening $(69,71)$. In these cases, surgical and/ or specific drugs targeting the aberrant receptors within the adrenal BMAH tissues led to complete or partial reversibility of metabolic morbidities with significantly improved health and reduced need for long-term numerous medications (71).

\section{Management of bilateral Al}

Unilateral adrenalectomy is recommended for unilateral AI with suspicious malignant lesions on imaging, or for certain lesions larger than $4-6 \mathrm{~cm}$, as well as for tumors with clear overt hormonal secretion (cortisol, aldosterone or catecholamines $)(1,10,12,53)$. However, the management is quite different in BMAH because the size of the tumors is not a criterion for surgery. As there is no clear consensus on the criteria defining abnormal cortisol secretion, the indication for adrenalectomy remains controversial (14); however, recent data on decreased survival of patients with abnormal cortisol suppression to dexamethasone tends to influence our management of patients with mild cortisol secretion. Bilateral adrenalectomy may be considered if urinary cortisol levels are higher than 3-4 times the upper limit of normal (ULN) with both adrenals having relatively symmetrical size (28). Many groups reported the benefits of unilateral adrenalectomy in small series of patients with BMAH and modest cortisol secretion $(<2-3$ times ULN): their combined data show a remission rate of hypercortisolism reaching $97 \%$ with a recurrence rate of $23 \%(78,79,80)$. The choice of which adrenal to remove remains uncertain: some choose to remove the adrenal with the largest size or the one with the highest uptake of iodo-cholesterol (yet limited availability depending on centers), whereas others rely on the results of adrenal venous sampling (selectivity criteria using free metanephrines remain poorly defined). Post-operative follow-up is essential to detect adrenal insufficiency that was present in $40 \%$ of cases in a French series (80). In 14 patients with bilateral AI and mild cortisol secretion, resection of the largest adenoma reduced cortisol excess in a significant way and improved the metabolic complications (81). To avoid hormonal replacement, concomitant total adrenalectomy and contralateral partial adrenalectomy was performed in a patient with $\mathrm{BMAH}$ using $3 \mathrm{D}$ adrenal gland printing and volumetric measurement before partial adrenalectomy to improve the determination of the remnant gland volume (82). Very recently, the experts from the European Society suggested that in selected patients, a unilateral adrenalectomy of the dominant lesion may be considered based on age of the patients, degree of cortisol excess, general condition and comorbidities and very importantly patient preference (14).

For AI with bilateral secretion of aldosterone confirmed by adrenal venous sampling, medical treatment with mineralocorticoids receptors antagonists remains the treatment of choice. 
Bilateral adrenalectomy is suggested for bilateral pheochromocytomas; however, the risk of adrenal insufficiency and the side effects of glucocorticoids replacement have led certain groups to perform partial tumor resection sparing the adrenal cortex particularly in the setting of genetic syndromes such as VHL and MEN2A where the risk of malignant tumors is very low (83). Infection-causing adrenal enlargement should be treated appropriately.

\section{Conclusion}

Overall, physicians face many uncertainties for the management of bilateral adrenal incidentalomas: (1) studies emitting guidelines for the work-up and management of bilateral AI remain scarce, (2) absence of consensus for the definition of mild cortisol excess Cushing's syndrome, (3) data on natural history of bilateral AI and studies evaluating cost/benefit of diagnostic and therapeutic strategies are lacking.

Nonetheless, bilateral AI represents a frequent pathology that requires conduction of thorough diagnostic and therapeutic approaches adapted to each case, taking into consideration many factors such as risk of malignancy and level of secretion. The distribution of etiologies is quite different from unilateral AI with a predominance of metastases, BMAH with mild cortisol excess, bilateral pheochromocytomas and CAH. Patients with bilateral disease in the context of BMAH, pheochromocytomas or CAH should be offered genetic counseling. Better knowledge of BMAH genetics will improve its early molecular diagnosis and abolish the biochemical and radiological investigations required for diagnosis and allow earlier therapy of affected individuals. Long-term prospective studies are needed to determine the evolution of bilateral AI and the risk of recurrence of hypercortisolism after unilateral adrenalectomy in cases with BMAH.

\section{Note added in proof}

A recent study revealed an incidence of $5 \%$ of mild glucocorticoid resistance (heterozygous NR3C1 mutations) in patients with adrenal incidentalomas, particularly if bilateral characterized by elevated UFC, incomplete suppression of cortisol and ACTH after overninght 1-mg dexamethasone test. This was associated with hypertension and/or biological hypercortisolism without clinical Cushing's signs (84)
Declaration of interest

The authors declare that there is no conflict of interest that could be perceived as prejudicing the impartiality of this review.

\section{Funding}

This work was supported in part by Fonds de Recherche du Québec-Santé (FRQS) to I B

\section{References}

1 Terzolo M, Stigliano A, Chiodini I, Loli P, Furlani L, Arnaldi G, Reimondo G, Pia A, Toscano V, Zini M et al. AME position statement on adrenal incidentaloma. European Journal of Endocrinology 2011164 851-870. (https://doi.org/10.1530/EJE-10-1147)

2 Bovio S, Cataldi A, Reimondo G, Sperone P, Novello S, Berruti A, Borasio P, Fava C, Dogliotti L, Scagliotti GV et al. Prevalence of adrenal incidentaloma in a contemporary computerized tomography series. Journal of Endocrinological Investigation 200629 298-302. (https://doi.org/10.1007/BF03344099)

3 Vassiliadi DA \& Tsagarakis S. Endocrine incidentalomas challenges imposed by incidentally discovered lesions. Nature Reviews Endocrinology 20117 668-680. (https://doi.org/10.1038/ nrendo.2011.92)

4 Song JH, Chaudhry FS \& Mayo-Smith WW. The incidental adrenal mass on CT: prevalence of adrenal disease in 1,049 consecutive adrenal masses in patients with no known malignancy. AJR: American Journal of Roentgenology 2008190 1163-1168. (https://doi. org/10.2214/AJR.07.2799)

5 Vassiliadi DA, Ntali G, Vicha E \& Tsagarakis S. High prevalence of subclinical hypercortisolism in patients with bilateral adrenal incidentalomas: a challenge to management. Clinical Endocrinology 201174 438-444. (https://doi.org/10.1111/j.13652265.2010.03963.x)

6 Hedeland H, Ostberg G \& Hokfelt B. On the prevalence of adrenocortical adenomas in an autopsy material in relation to hypertension and diabetes. Acta Medica Scandinavica 1968184 211-214. (https://doi.org/10.1111/j.0954-6820.1968.tb02445.x)

7 Zeiger MA, Thompson GB, Duh QY, Hamrahian AH, Angelos P, Elaraj D, Fishman E, Kharlip J, American Association of Clinical E \& American Association of Endocrine S. The American Association of Clinical Endocrinologists and American Association of Endocrine Surgeons medical guidelines for the management of adrenal incidentalomas. Endocrine Practice 200915 (Supplement 1) 1-20. (https://doi.org/10.4158/EP.15.S1.1)

8 Boland GW, Blake MA, Hahn PF \& Mayo-Smith WW. Incidental adrenal lesions: principles, techniques, and algorithms for imaging characterization. Radiology 2008249 756-775. (https://doi. org/10.1148/radiol.2493070976)

9 Young WF Jr. Management approaches to adrenal incidentalomas. A view from Rochester, Minnesota. Endocrinology Metabolism Clinics of North America 200029 159-185. (https://doi.org/10.1016/S08898529(05)70122-5)

10 Young WF Jr. Clinical practice. The incidentally discovered adrenal mass. New England Journal of Medicine 2007356 601-610. (https:// doi.org/10.1056/NEJMcp065470)

11 Patrova J, Jarocka I, Wahrenberg H \& Falhammar H. Clinical outcomes in adrenal incidentaloma: experience from one center. Endocrine Practice 201521 870-877. (https://doi.org/10.4158/EP15618.OR)

12 Tabarin A, Bardet S, Bertherat J, Dupas B, Chabre O, Hamoir E, Laurent F, Tenenbaum F, Cazalda M, Lefebvre H et al. Exploration and management of adrenal incidentalomas. French Society of Endocrinology Consensus. Annales d'Endocrinologie 200869 487-500. (https://doi.org/10.1016/j.ando.2008.09.003) 
13 Mantero F, Terzolo M, Arnaldi G, Osella G, Masini AM, Ali A, Giovagnetti M, Opocher G \& Angeli A. A survey on adrenal incidentaloma in Italy. Study Group on Adrenal Tumors of the Italian Society of Endocrinology. Journal of Clinical Endocrinology and Metabolism 200085 637-644.

14 Fassnacht M, Arlt W, Bancos I, Dralle H, Newell-Price J, Sahdev A, Tabarin A, Terzolo M, Tsagarakis S \& Dekkers OM. Management of adrenal incidentalomas: European Society of Endocrinology Clinical Practice Guideline in collaboration with the European Network for the Study of Adrenal Tumors. European Journal of Endocrinology 2016 175 G1-G34. (https://doi.org/10.1530/EJE-16-0467)

15 Cawood TJ, Hunt PJ, O'Shea D, Cole D \& Soule S. Recommended evaluation of adrenal incidentalomas is costly, has high false-positive rates and confers a risk of fatal cancer that is similar to the risk of the adrenal lesion becoming malignant; time for a rethink? European Journal of Endocrinology 2009161 513-527. (https://doi.org/10.1530/ EJE-09-0234)

16 Angeli A, Osella G, Ali A \& Terzolo M. Adrenal incidentaloma: an overview of clinical and epidemiological data from the National Italian Study Group. Hormone Research 199747 279-283. (https://doi. org/10.1159/000185477)

17 Barzon L, Scaroni C, Sonino N, Fallo F, Gregianin M, Macri C \& Boscaro M. Incidentally discovered adrenal tumors: endocrine and scintigraphic correlates. Journal of Clinical Endocrinology and Metabolism 199883 55-62.

18 Torre I, Ribera G, Pavia M \& Angelillo IF. A seroepidemiologic survey on brucellosis antibodies in southern Italy. Infection 199725 150-153. (https://doi.org/10.1007/BF02113602)

19 White PC \& New MI. Genetic basis of endocrine disease 2: congenital adrenal hyperplasia due to 21-hydroxylase deficiency. Journal of Clinical Endocrinology and Metabolism 199274 6-11.

20 Jaresch S, Kornely E, Kley HK \& Schlaghecke R. Adrenal incidentaloma and patients with homozygous or heterozygous congenital adrenal hyperplasia. Journal of Clinical Endocrinology and Metabolism 199274 685-689. (https://doi.org/10.1210/ jcem.74.3.1311000)

21 Kasperlik-Zeluska AA, Roslonowska E, Slowinska-Srzednicka J, Migdalska B, Jeske W, Makowska A \& Snochowska H. Incidentally discovered adrenal mass (incidentaloma): investigation and management of 208 patients. Clinical Endocrinology 199746 29-37. (https://doi. org/10.1046/j.1365-2265.1997.d01-1751.x)

22 Noguchi S, Torii R, Shimabukuro I, Yamasaki K, Kido T, Yoshii C, Mukae H \& Yatera K. Adrenal insufficiency associated with small cell lung cancer: a case report and literature review. Journal of UOEH 2016 38 155-162. (https://doi.org/10.7888/juoeh.38.155)

23 Nouralizadeh A, Afyouni A, Shakiba B \& Radhi FK. Simultaneous bilateral laparoscopic adrenalectomy for adrenal metastases of renal cell carcinoma: a case report. Journal of Endourology Case Reports 2017 3 142-145. (https://doi.org/10.1089/cren.2017.0062)

24 Ozturk H. Bilateral synchronous adrenal metastases of renal cell carcinoma: a case report and review of the literature. Oncology Letters 20159 1897-1901. (https://doi.org/10.3892/ol.2015.2915)

25 Laurent C, Casasnovas O, Martin L, Chauchet A, Ghesquieres H, Aussedat G, Fornecker LM, Bologna S, Borot S, Laurent K et al. Adrenal lymphoma: presentation, management and prognosis. Queensland Journal of Medicine 2017110 103-109. (https://doi. org/10.1093/qjmed/hcw174).

26 Tadjine M, Lampron A, Ouadi L, Horvath A, Stratakis CA \& Bourdeau I. Detection of somatic beta-catenin mutations in primary pigmented nodular adrenocortical disease (PPNAD). Clinical Endocrinology 200869 367-373. (https://doi.org/10.1111/j.13652265.2008.03273.x)

27 Gleason PE, Weinberger MH, Pratt JH, Bihrle R, Dugan J, Eller D $\&$ Donohue JP. Evaluation of diagnostic tests in the differential diagnosis of primary aldosteronism: unilateral adenoma versus bilateral micronodular hyperplasia. Journal of Urology $1993 \mathbf{1 5 0}$ 1365-1368. (https://doi.org/10.1016/S0022-5347(17)35781-6)

$28 \mathrm{El}$ Ghorayeb N, Bourdeau I \& Lacroix A. Multiple aberrant hormone receptors in Cushing's syndrome. European Journal of Endocrinology 2015173 M45-M60. (https://doi.org/10.1530/EJE-15-0200)

29 Mircescu H, Jilwan J, N’Diaye N, Bourdeau I, Tremblay J, Hamet P \& Lacroix A. Are ectopic or abnormal membrane hormone receptors frequently present in adrenal Cushing's syndrome? Journal of Clinical Endocrinology and Metabolism 200085 3531-3536.

30 Reznik Y, Lefebvre H, Rohmer V, Charbonnel B, Tabarin A, Rodien P, Lecomte P, Bardet S, Coffin C, Mahoudeau J et al. Aberrant adrenal sensitivity to multiple ligands in unilateral incidentaloma with subclinical autonomous cortisol hypersecretion: a prospective clinical study. Clinical Endocrinology 200461 311-319. (https://doi. org/10.1111/j.1365-2265.2004.02048.x)

31 Libe R, Coste J, Guignat L, Tissier F, Lefebvre H, Barrande G, Ajzenberg C, Tauveron I, Clauser E, Dousset B et al. Aberrant cortisol regulations in bilateral macronodular adrenal hyperplasia: a frequent finding in a prospective study of 32 patients with overt or subclinical Cushing's syndrome. European Journal of Endocrinology 2010163 129-138. (https://doi.org/10.1530/EJE-10-0195)

32 Hofland J, Hofland LJ, van Koetsveld PM, Steenbergen J, de Herder WW, van Eijck CH, de Krijger RR, van Nederveen FH, van Aken MO, de Groot JW et al. ACTH-independent macronodular adrenocortical hyperplasia reveals prevalent aberrant in vivo and in vitro responses to hormonal stimuli and coupling of argininevasopressin type 1a receptor to 11beta-hydroxylase. Orphanet Journal of Rare Diseases 20138 142. (https://doi.org/10.1186/1750-1172-8142)

33 Hsiao HP, Kirschner LS, Bourdeau I, Keil MF, Boikos SA, Verma S, Robinson-White AJ, Nesterova M, Lacroix A \& Stratakis CA. Clinical and genetic heterogeneity, overlap with other tumor syndromes, and atypical glucocorticoid hormone secretion in adrenocorticotropinindependent macronodular adrenal hyperplasia compared with other adrenocortical tumors. Journal of Clinical Endocrinology and Metabolism 200994 2930-2937. (https://doi.org/10.1210/jc.20090516)

34 Beuschlein F, Fassnacht M, Assie G, Calebiro D, Stratakis CA Osswald A, Ronchi CL, Wieland T, Sbiera S, Faucz FR et al. Constitutive activation of PKA catalytic subunit in adrenal Cushing's syndrome. New England Journal of Medicine 2014370 1019-1028. (https://doi.org/10.1056/NEJMoa1310359)

35 Lacroix A. Heredity and cortisol regulation in bilateral macronodular adrenal hyperplasia. New England Journal of Medicine 2013369 2147-2149. (https://doi.org/10.1056/NEJMe1312792)

36 Louiset E, Duparc C, Young J, Renouf S, Tetsi Nomigni M, Boutelet I, Libe R, Bram Z, Groussin L, Caron P et al. Intraadrenal corticotropin in bilateral macronodular adrenal hyperplasia. New England Journal of Medicine 2013369 2115-2125. (https://doi.org/10.1056/ NEJMoa1215245)

37 Alencar GA, Fragoso MC, Yamaga LY, Lerario AM \& Mendonca BB (18)F-FDG-PET/CT imaging of ACTH-independent macronodular adrenocortical hyperplasia (AIMAH) demonstrating increased (18) F-FDG uptake. Journal of Clinical Endocrinology and Metabolism 2011 96 3300-3301. (https://doi.org/10.1210/jc.2011-1397)

38 Doppman JL, Chrousos GP, Papanicolaou DA, Stratakis CA, Alexander HR \& Nieman LK. Adrenocorticotropin-independent macronodular adrenal hyperplasia: an uncommon cause of primary adrenal hypercortisolism. Radiology 2000216 797-802. (https://doi. org/10.1148/radiology.216.3.r00au40797)

39 Cavalcante IP, Nishi M, Zerbini MCN, Almeida MQ, Brondani VB, Botelho M, Tanno FY, Srougi V, Chambo JL, Mendonca BB et al. The role of ARMC5 in human cell cultures from nodules of primary macronodular adrenocortical hyperplasia (PMAH). Molecular and Cellular Endocrinology 2018460 36-46. (https://doi.org/10.1016/j. mce.2017.06.027) 
40 Lenders JW, Duh QY, Eisenhofer G, Gimenez-Roqueplo AP, Grebe SK, Murad MH, Naruse M, Pacak K, Young WF Jr \& Endocrine S. Pheochromocytoma and paraganglioma: an endocrine society clinical practice guideline. Journal of Clinical Endocrinology and Metabolism 201499 1915-1942. (https://doi.org/10.1210/ jc.2014-1498)

41 Moramarco J, El Ghorayeb N, Dumas N, Nolet S, Boulanger L, Burnichon N, Lacroix A, Elhaffaf Z, Gimenez Roqueplo AP, Hamet P et al. Pheochromocytomas are diagnosed incidentally and at older age in neurofibromatosis type 1. Clinical Endocrinology 201786 332-339. (https://doi.org/10.1111/cen.13265)

42 Burnichon N, Cascon A, Schiavi F, Morales NP, Comino-Mendez I, Abermil N, Inglada-Perez L, de Cubas AA, Amar L, Barontini M et al. MAX mutations cause hereditary and sporadic pheochromocytoma and paraganglioma. Clinical Cancer Research 201218 2828-2837. (https://doi.org/10.1158/1078-0432.CCR-12-0160)

43 Malayeri AA, Zaheer A, Fishman EK \& Macura KJ. Adrenal masses: contemporary imaging characterization. Journal of Computer Assisted Tomography 201337 528-542. (https://doi.org/10.1097/ RCT.0b013e31828b690d)

44 Patocs A, Toth M, Barta C, Sasvari-Szekely M, Varga I, Szucs N, Jakab C, Glaz E \& Racz K. Hormonal evaluation and mutation screening for steroid 21-hydroxylase deficiency in patients with unilateral and bilateral adrenal incidentalomas. European Journal of Endocrinology 2002147 349-355. (https://doi.org/10.1530/ eje.0.1470349)

45 Falhammar H \& Torpy DJ. Congenital adrenal hyperplasia due to 21-hydroxylase deficiency presenting as adrenal incidentaloma: a systematic review and meta-analysis. Endocrine Practice 201622 736-752. (https://doi.org/10.4158/EP151085.RA)

46 Albiger NM, Occhi G, Sanguin F, Iacobone M, Casarrubea G, Ferasin S, Mantero F \& Scaroni C. Adrenal nodules in patients with Cushing's disease: prevalence, clinical significance and follow-up. Journal of Endocrinological Investigation 201134 e204-e209.

47 Kenney PJ, Wagner BJ, Rao P \& Heffess CS. Myelolipoma: CT and pathologic features. Radiology 1998208 87-95. (https://doi. org/10.1148/radiology.208.1.9646797)

48 Zattoni D, Balzarotti R \& Rosso R. The management of bilateral myelolipoma: case report and review of the literature. International Journal of Surgery Case Reports 201512 31-36. (https://doi. org/10.1016/j.ijscr.2015.04.021)

49 Shenoy VG, Thota A, Shankar R \& Desai MG. Adrenal myelolipoma: controversies in its management. Indian Journal of Urology 201531 94-101. (https://doi.org/10.4103/0970-1591.152807)

50 Rog CJ, Rosen DG \& Gannon FH. Bilateral adrenal histoplasmosis in an immunocompetent man from Texas. Medical Mycology Case Reports 201614 4-7. (https://doi.org/10.1016/j.mmcr.2016.11.006)

51 Rao RH, Vagnucci AH \& Amico JA. Bilateral massive adrenal hemorrhage: early recognition and treatment. Annals of Internal Medicine 1989110 227-235. (https://doi.org/10.7326/0003-4819110-3-227)

52 Presotto F, Fornasini F, Betterle C, Federspil G \& Rossato M. Acute adrenal failure as the heralding symptom of primary antiphospholipid syndrome: report of a case and review of the literature. European Journal of Endocrinology 2005153 507-514. (https://doi.org/10.1530/eje.1.02002)

$53 \mathrm{NIH}$ state-of-the-science statement on management of the clinically inapparent adrenal mass ("incidentaloma"). NIH Consensus and Stateof-the-Science Statements 200219 1-25.

54 Eisenhofer G \& Peitzsch M. Laboratory evaluation of pheochromocytoma and paraganglioma. Clinical Chemistry 201460 1486-1499. (https://doi.org/10.1373/clinchem.2014.224832)

55 White PC \& Speiser PW. Congenital adrenal hyperplasia due to 21-hydroxylase deficiency. Endocrine Reviews 200021 245-291.

56 Terzolo M, Pia A, Ali A, Osella G, Reimondo G, Bovio S, Daffara F, Procopio M, Paccotti P, Borretta G et al. Adrenal incidentaloma: a new cause of the metabolic syndrome? Journal of Clinical Endocrinology and Metabolism 200287 998-1003. (https://doi. org/10.1210/jcem.87.3.8277)

57 Chiodini I. Clinical review: diagnosis and treatment of subclinical hypercortisolism. Journal of Clinical Endocrinology and Metabolism 201196 1223-1236. (https://doi.org/10.1210/jc.2010-2722)

58 Tauchmanova L, Rossi R, Biondi B, Pulcrano M, Nuzzo V, Palmieri EA, Fazio S \& Lombardi G. Patients with subclinical Cushing's syndrome due to adrenal adenoma have increased cardiovascular risk. Journal of Clinical Endocrinology and Metabolism 200287 4872-4878. (https:// doi.org/10.1210/jc.2001-011766)

59 Di Dalmazi G, Pasquali R, Beuschlein F \& Reincke M. Subclinical hypercortisolism: a state, a syndrome, or a disease? European Journal of Endocrinology 2015173 M61-M71. (https://doi.org/10.1530/EJE15-0272)

60 Di Dalmazi G, Vicennati V, Garelli S, Casadio E, Rinaldi E, Giampalma E, Mosconi C, Golfieri R, Paccapelo A, Pagotto U et al. Cardiovascular events and mortality in patients with adrenal incidentalomas that are either non-secreting or associated with intermediate phenotype or subclinical Cushing's syndrome: a 15-year retrospective study. Lancet Diabetes and Endocrinology 20142 396-405. (https://doi.org/10.1016/S2213-8587(13)70211-0)

61 Debono M, Bradburn M, Bull M, Harrison B, Ross RJ \& NewellPrice J. Cortisol as a marker for increased mortality in patients with incidental adrenocortical adenomas. Journal of Clinical Endocrinology and Metabolism 201499 4462-4470. (https://doi.org/10.1210/ jc.2014-3007)

62 Morelli V, Palmieri S, Salcuni AS, Eller-Vainicher C, Cairoli E, Zhukouskaya V, Scillitani A, Beck-Peccoz P \& Chiodini I. Bilateral and unilateral adrenal incidentalomas: biochemical and clinical characteristics. European Journal of Endocrinology 2013168 235-241. (https://doi.org/10.1530/EJE-12-0777)

63 Vassiliadi DA, Ntali G, Stratigou T, Adali M \& Tsagarakis S. Aberrant cortisol responses to physiological stimuli in patients presenting with bilateral adrenal incidentalomas. Endocrine 201140 437-444. (https://doi.org/10.1007/s12020-011-9490-1)

64 Androulakis II, Kaltsas GA, Markou A, Tseniklidi E, Kafritsa P, Pappa T, Papanastasiou L \& Piaditis GP. The functional status of incidentally discovered bilateral adrenal lesions. Clinical Endocrinology 201175 44-49. (https://doi.org/10.1111/j.13652265.2011.04013.x)

65 Vassilatou E, Vryonidou A, Ioannidis D, Paschou SA, Panagou M \& Tzavara I. Bilateral adrenal incidentalomas differ from unilateral adrenal incidentalomas in subclinical cortisol hypersecretion but not in potential clinical implications. European Journal of Endocrinology 2014171 37-45. (https://doi.org/10.1530/EJE-13-0848)

66 Pasternak JD, Seib CD, Seiser N, Tyrell JB, Liu C, Cisco RM, Gosnell JE, Shen WT, Suh I \& Duh QY. Differences between bilateral adrenal incidentalomas and unilateral lesions. JAMA Surgery 2015 150 974-978. (https://doi.org/10.1001/jamasurg.2015.1683)

67 Vassiliadi DA, Tzanela M, Tsatlidis V, Margelou E, Tampourlou M, Mazarakis N, Piaditis G \& Tsagarakis S. Abnormal responsiveness to dexamethasone-suppressed CRH test in patients with bilateral adrenal incidentalomas. Journal of Clinical Endocrinology and Metabolism 2015100 3478-3485. (https://doi.org/10.1210/JC.20151653)

68 Assie G, Libe R, Espiard S, Rizk-Rabin M, Guimier A, Luscap W, Barreau O, Lefevre L, Sibony M, Guignat L et al. ARMC5 mutations in macronodular adrenal hyperplasia with Cushing's syndrome. New England Journal of Medicine 2013369 2105-2114. (https://doi. org/10.1056/NEJMoa1304603)

69 Alencar GA, Lerario AM, Nishi MY, Mariani BM, Almeida MQ, Tremblay J, Hamet P, Bourdeau I, Zerbini MC, Pereira MA et al. ARMC5 mutations are a frequent cause of primary macronodular adrenal hyperplasia. Journal of Clinical Endocrinology and Metabolism 201499 E1501-E1509. (https://doi.org/10.1210/jc.2013-4237) 
70 Correa R, Zilbermint M, Berthon A, Espiard S, Batsis M, Papadakis GZ, Xekouki P, Lodish MB, Bertherat J, Faucz FR et al. The ARMC5 gene shows extensive genetic variance in primary macronodular adrenocortical hyperplasia. European Journal of Endocrinology 2015173 435-440. (https://doi.org/10.1530/EJE-150205)

71 Bourdeau I, Oble S, Magne F, Levesque I, Caceres-Gorriti KY, Nolet S, Awadalla P, Tremblay J, Hamet P, Fragoso MC et al. ARMC5 mutations in a large French-Canadian family with cortisol-secreting beta-adrenergic/vasopressin responsive bilateral macronodular adrenal hyperplasia. European Journal of Endocrinology $2016 \mathbf{1 7 4}$ 85-96. (https://doi.org/10.1530/EJE-15-0642)

72 Albiger NM, Regazzo D, Rubin B, Ferrara AM, Rizzati S, Taschin E, Ceccato F, Arnaldi G, Pecori Giraldi F, Stigliano A et al. A multicenter experience on the prevalence of ARMC5 mutations in patients with primary bilateral macronodular adrenal hyperplasia: from genetic characterization to clinical phenotype. Endocrine 201755 959-968. (https://doi.org/10.1007/s12020-016-0956-z)

73 Elbelt U, Trovato A, Kloth M, Gentz E, Finke R, Spranger J, Galas D, Weber S, Wolf C, Konig K et al. Molecular and clinical evidence for an ARMC5 tumor syndrome: concurrent inactivating germline and somatic mutations are associated with both primary macronodular adrenal hyperplasia and meningioma. Journal of Clinical Endocrinology and Metabolism 2015100 E119-E128. (https://doi.org/10.1210/ jc.2014-2648)

74 Emms H, Tsirou I, Cranston T, Tsagarakis S \& Grossman AB. Do patients with incidentally discovered bilateral adrenal nodules represent an early form of ARMC5-mediated bilateral macronodular hyperplasia? Endocrine 201653 801-808. (https://doi.org/10.1007/ s12020-016-0988-4)

75 Mazzuco TL, Durand J, Chapman A, Crespigio J \& Bourdeau I. Genetic aspects of adrenocortical tumours and hyperplasias. Clinical Endocrinology 201277 1-10. (https://doi.org/10.1111/j.13652265.2012.04403.x)

76 Fragoso MC, Alencar GA, Lerario AM, Bourdeau I, Almeida MQ, Mendonca BB \& Lacroix A. Genetics of primary macronodular adrenal hyperplasia. Journal of Endocrinology 2015224 R31-R43. (https://doi.org/10.1530/JOE-14-0568)

77 De Venanzi A, Alencar GA, Bourdeau I, Fragoso MC \& Lacroix A. Primary bilateral macronodular adrenal hyperplasia. Current Opinion in Endocrinology, Diabetes and Obesity 201421 177-184. (https://doi. org/10.1097/MED.0000000000000061)

78 Albiger NM, Ceccato F, Zilio M, Barbot M, Occhi G, Rizzati S, Fassina A, Mantero F, Boscaro M, Iacobone M et al. An analysis of different therapeutic options in patients with Cushing's syndrome due to bilateral macronodular adrenal hyperplasia: a single-centre experience. Clinical Endocrinology 201582 808-815. (https://doi. org/10.1111/cen.12763)

79 Xu Y, Rui W, Qi Y, Zhang C, Zhao J, Wang X, Wu Y, Zhu Q, Shen Z, Ning $G$ et al. The role of unilateral adrenalectomy in corticotropinindependent bilateral adrenocortical hyperplasias. World Journal of Surgery 201337 1626-1632. (https://doi.org/10.1007/s00268-0132059-9)

80 Debillon E, Velayoudom-Cephise FL, Salenave S, Caron P, Chaffanjon P, Wagner T, Massoutier M, Lambert B, Benoit M, Young J et al. Unilateral adrenalectomy as a first-line treatment of Cushing's syndrome in patients with primary bilateral macronodular adrenal hyperplasia. Journal of Clinical Endocrinology and Metabolism 2015100 4417-4424. (https://doi.org/10.1210/jc.2015-2662)

81 Perogamvros I, Vassiliadi DA, Karapanou O, Botoula E, Tzanela M $\&$ Tsagarakis S. Biochemical and clinical benefits of unilateral adrenalectomy in patients with subclinical hypercortisolism and bilateral adrenal incidentalomas. European Journal of Endocrinology 2015173 719-725. (https://doi.org/10.1530/EJE-15-0566)

82 Srougi V, Rocha BA, Tanno FY, Almeida MQ, Baroni RH, Mendonca BB, Srougi M, Fragoso MC \& Chambo JL. The use of three-dimensional printers for partial adrenalectomy: estimating the resection limits. Urology 201690 217-220. (https://doi.org/10.1016/j. urology.2015.11.043)

83. Castinetti F, Taieb D, Henry JF, Walz M, Guerin C, Brue T, ConteDevolx B, Neumann HP \& Sebag F. MANAGEMENT OF ENDOCRINE DISEASE: outcome of adrenal sparing surgery in heritable pheochromocytoma. European Journal of Endocrinology 2016174 R9-R18.

84 Vitellius G, Trabado S, Hoeffel C, Bouligand J, Bennet A, Castinetti F, Decoudier B, Guiochon-Mantel A, Lombes M, Delemer $\mathrm{B}$, and investigators of the MUTA-GR Study. Significant prevalence of NR3C1 mutations in incidentally discovered bilateral adrenal hyperplasia: results of the French MUTA-GR Study. European Journal of Endocrinology 2018178 411-423. (https://doi.org/10.1530/EJE-17-1071)

Received 19 April 2018 Accepted 10 May 2018 